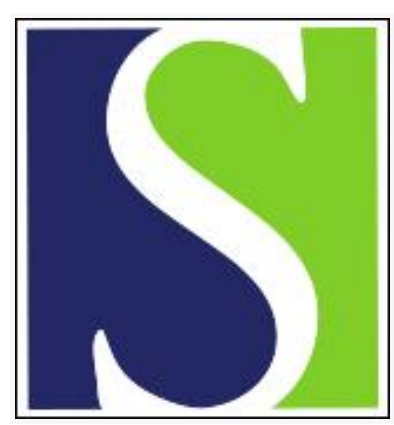

Scand J Work Environ Health 2011;37(4):259-261

https://doi.org/10.5271/sjweh.3172

Published online: 06 Jun 2011, Issue date: Jul 2011

Understanding the causal relations between psychosocial factors at work and health - a circular process

by Kompier MAJ, Taris TW

Affiliation: Behavioural Science Institute, Radboud University Nijmegen, Nijmegen, The Netherlands. M.Kompier@psych.ru.nl

Refers to the following texts of the Journal: 2003;29(1):1-4

2005;31(1):3-14 2006;32(6):463-472 2011;37(4):276-287

The following articles refer to this text: 2012;38(1):38-46;

2012;38(3):238-246; 2013;39(6):535-549

Key terms: causal relation; causality; editorial; harassment; mental stress; mobbing; prospective study; psychological health; psychosocial factor; workplace bullying

This article in PubMed: www.ncbi.nlm.nih.gov/pubmed/21643622

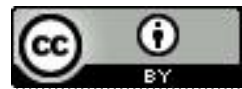




\section{Understanding the causal relations between psychosocial factors at work and health - a circular process}

One of the aims of this Journal is to publish longitudinal studies in occupational health psychology that shed more light on the causal relations between the psychosocial work environment and health (1). Schematically, we can distinguish among three types of causality: (i) normal causation (A impacts on $B$, for example, high job demands lead to high levels of exhaustion), (ii) reverse causation (B affects $A$, eg, exhausted workers may evaluate their jobs as more demanding, leading them to report higher levels of job demands), and (iii) reciprocal causation ( $A$ impacts on $B$ and $B$ impacts on $A$, eg, job demands and exhaustion affect each other mutually).

The current issue contains an excellent example of a paper that investigates these different types of causality. It is a paper by Finne, Knardahl and Lau (2). In a two-year prospective study, these authors analyzed the across-time associations between workplace bullying and mental distress, considering normal, reversed, as well as reciprocal causation. According to Einarsen et al (3), bullying refers to "... harassing, offending, socially excluding someone or negatively affecting someone's work task. In order for the label bullying (or mobbing) to be applied to a particular activity, interaction, or process it has to occur repeatedly and regularly (eg, weekly) and over a period of time (eg, about six months). Bullying is an escalating process in the course of which the person confronted ends up in an inferior position and becomes the target of systematic negative social acts. A conflict cannot be called bullying if the incident is an isolated event or if two parties of approximately equal "strength" are in conflict" (p15).

In occupational health psychology, interest in workplace bullying, mobbing, and harassment has grown since the 1990s, but accounts of workplace bullying are already present in the classics of work psychology: Frederick Taylor's (4) scientific management and Roethlisberger \& Dickson's (5) Hawthorne studies. One century ago, Taylor provided the example of a novice golf caddy who is so eager in collecting balls that he is threatened and forced to work more slowly by his more experienced fellow caddies because otherwise it would affect their earnings. Roethlisberger \& Dickson's observational study in the famous bank wiring room shows how outliers, that is, workers who worked either too fast or too slow according to the informal group norms, were verbally and physically corrected by their colleagues, for example by the practice of "binging" (hitting them sharply on the upper arm).

Clearly, bullying is not a new phenomenon and one may even doubt whether it is a growing problem. Still, the gradual change in focus from a collective social psychological to an individual personal perspective has provided a clearer picture of the pertinent negative consequences for its victims (6, p162). For example, cognitive theory of trauma (7) explains these consequences by assuming that bullying violates victims' basic beliefs of the world as benevolent and meaningful, and the self as worthy and capable of coping with difficulties. In this view, being bullied may have adverse consequences such as mental distress. However, the literature's emphasis on the individual has also led to approaches in which the bullied and socially isolated employee is held responsible for his or her own misery. Work and organizational psychology has a long tradition in stressing such individual explanations, with early explanations of work accidents and repetitive strain injury more or less disregarding contextual factors and focusing on individual characteristics (eg, neuroticism) that are assumed to have caused these phenomena (8). Finne et al (2) propose that high levels of distress could be one such characteristic. Thus, there are at least two explanations for a possible association between bullying and mental distress, with one stating that bullying causes distress and the other proposing that distress results in higher levels of bullying (or at least the reporting thereof). 
In investigating the possibly bi-directional associations between mental distress and bullying, Finne et al followed a clear, elaborate and exemplary conceptual and analytical approach. They utilized a full panel design: that is, all important variables (ie, both mental distress and bullying) were measured at both study waves. Using this design, Finne et al analyzed both the synchronous (cross-sectional) associations between the variables of interest within each wave, and the lagged (longitudinal) relations between bullying (mental distress) at baseline and mental distress (bullying) at follow-up, whilst correcting for baseline levels of mental distress (bullying). Finally, they compared four theoretically meaningful subgroups on the basis of different patterns of exposure to bullying. One group was not bullied during the study period; a second group was bullied at both study waves; the third group was bullied at baseline but not at follow-up; the final group was not bullied at baseline but was bullied at follow-up. These analyses provided support for reciprocal causation: self-reported workplace bullying predicted mental distress two years later (indicative of normal causation); in turn, mental distress predicted bullying across time (indicative of reverse causation). The authors conclude that the associations between workplace bullying and mental distress constitute a vicious circle, with bullying leading to mental distress, distress leading to higher levels of bullying, and so forth - a challenging and practically relevant conclusion that could not have been reached if the authors had used a less sophisticated study design or a less elaborate strategy to analyze their data. But it is also a conclusion that raises the question how these "reverse causation" effects of mental distress on bullying could be explained.

One of the conditions that must be met to defend the case of causality is theoretical plausibility (1). In occupational health psychology, normal causation (with psychosocial work characteristics affecting individual-level outcomes) is relatively well understood. Two mechanisms stand out: a psychophysiological mechanism and a behavioral lifestyle mechanism. The first mechanism holds that long-term exposure to high work stress without having sufficient possibilities for recovery affects health in the long run via sustained activation of the autonomic nervous system and enhanced neuroendocrine responses. The second path, involving an (un)healthy lifestyle, states that stress undermines self-control and therefore may contribute to unhealthy behavior, both at work (risk taking) and outside work (unhealthy habits such as high alcohol intake, smoking, and lack of exercise). But how can reverse effects be explained? It is likely that both perceptual and behavioral mechanisms are involved (9). For example, unhealthy (eg, depressive) employees may evaluate their environment negatively (ie, the reported environmental "changes" are mainly a matter of changed perceptions). However, worker behavior may also create real changes in the work environment. For instance, distressed employees may underperform and therefore receive less support from colleagues or supervisors, they may not participate in social meetings with colleagues, prefer to remain alone and therefore become isolated and ridiculed, be given the "silent treatment", and so forth - all of which may well be considered forms of bullying. One of the assets of the Finne et al study is that it discusses various explanations as to how such reverse causation processes may occur, and it would be interesting for future research to see which - if any - of these accounts holds true.

What does this mean for research in the broader area of work and health psychology? First, it is important to recognize that it is often at least possible that normal causation is not the only mechanism accounting for the associations between environmental characteristics and individual "outcomes". Indeed, it may not even the be most important mechanism. This is nicely illustrated by the Finne et al study, where normal causation was relatively weak and reversed causation surprisingly strong. Thus, future research seeking to understand the processes linking psychosocial work characteristics, health and well-being should not solely focus on traditional conceptualizations of these processes, but also consider alternative accounts.

Secondly, acknowledging that causation may be a two-way street will have implications for the research designs that researchers use in occupational health psychology. Longitudinal designs are indispensable, and in order to examine reverse causation these designs should take the form of a complete (rather than a partial) panel study. That is, all concepts of interest (unless they are stable concepts - such 
as sex - or a priori predictable - such as age) should be measured at all occasions. This ensures that both normal and reverse causation issues can be tested.

Thirdly, in order to test the mechanisms accounting for both normal and reverse causation in work stress research, we expect that mediation analysis will become increasingly important. It is all very well to see that A impacts B across time, but in order to identify the process that is responsible for this association it will be necessary to examine the concepts that are proposed to mediate this association. For example, a researcher may argue that distressed workers are expected to isolate themselves and that this leads to bullying. In order to test this reasoning, this researcher should not only measure distress and the degree to which workers consider themselves as being bullied, but also include - preferably "objective" - measures of social isolation in his or her research design. A proper examination of these mediation processes requires that two-wave longitudinal research designs be extended with a third wave, eg, to test whether the longitudinal association between distress (as measured at the first wave) and bullying (as measured at the third wave) can be interpreted in terms of higher levels of social isolation (as measured at the second wave) (10).

In conclusion, we argue that in occupational health psychology (i) cross-sectional studies are of little help in examining issues of causality; since (ii) cross-sectional associations between pairs of variables cannot readily be interpreted in terms of normal, reversed or reciprocal causation. In addition, (iii) more careful theorizing on the mechanisms accounting for such associations between pairs of variables is needed; and (iv) these processes cannot be disentangled without extended longitudinal research designs, involving complete data for at least three study waves. Obviously, complying with these recommendations will substantially increase the time and resources needed to collect data. However, this drawback will be compensated for by the increased understanding that will result from adhering to these recommendations - a consequence that is likely to result in practical interventions that will be more effective in improving people's working lives. Is that not what we are after?

\section{References}

1. Taris T, Kompier M. Challenges in longitudinal designs in occupational health psychology. Scand J Work Environ Health. 2003;29 (1):1-4.

2. Finne LB, Knardahl S, Lau B. Workplace bullying and mental distress: A prospective study of Norwegian Employees. Scand J Work Environ Health. 2011;37(4):276-287. doi:10.5271/sjweh.3156.

3. Einarsen S, Hoel H, Zapf D, Cooper CL. The concept of bullying at work: The European tradition. In Einarsen S, Hoel H, Zapf D, Cooper CL (eds). Bullying and emotional abuse in the workplace: International perspectives in research and practice. London: Taylor \& Francis; 2003.

4. Taylor FW. Principles of scientific management. New York: Harper; 1911.

5 Roethlisberger FJ, Dickson WJ. Management and the worker. Cambridge, MA: Harvard University Press; 1939.

6. Agervold M. Bullying at work: a discussion of definitions and prevalence, based on an empirical study. Scand J Psychology. 2007;48(2):161-172. doi:10.1111/j.1467-9450.2007.00585.x

7. Janoff-Bulman R. Shattered assumptions - towards a new psychology of trauma. New York: The Free Press; 1992.

8. Dembe, AE. The changing nature of office work: effects on repetitive strain injuries. Occupational Medicine. 1999;14(1):61-72.

9. De Lange AH, Taris TW, Kompier MAJ, Houtman ILD, Bongers PM (2005). Different mechanisms to explain the reversed effects of mental health on work characteristics. Scand J Work Environ Health. 2005;31(1):3-14.

10. Taris TW, Kompier MAJ. Games researchers play: Extreme groups analysis and mediation analysis in longitudinal occupational health research. Scand J Work Environ Health. 2006;32(6):463-472.

Michiel AJ Kompier

Behavioural Science Institute

Radboud University Nijmegen,

Nijmegen, The Netherlands

[E-mail: M.Kompier@psych.ru.nl]
Toon W Taris

Department of Work and Organizational Psychology

Utrecht University

Utrecht, The Netherlands

[E-mail: t.taris@uu.nl] 
